\title{
PROSEDUR PEMERIKSAAN RADIOGRAFI CLAVICULA DENGAN KLINIS FRAKTUR DI RSUD RAA SOEWONDO PATI
}

\author{
${ }^{1}$ Mohamad Affan Haqqi ${ }^{2}$ Nanang Sulaksono \\ 1) RSUD Jombang \\ ${ }^{2)}$ Poltekkes Kemenkes Semarang \\ Corresponding author: Mohamad Affan Haqqi \\ Email: affanhaqqi11@gmail.com
}

\begin{abstract}
Background: Clavicula examination procedure with clinical fractures in radiology installation RAA Soewondo Pati Hospital was using only Antero Posterior (AP) projection. The purpose of this research is to know the clavicle examination procedure with clinical fractures and find out the reasons for using Antero Posterior (AP) projections.

Methods: Type of this research is qualitative research with approach case studies. Data were collected by observation, in-depth interviews, and documentation. This research took place in the radiology installation of RAA Soewondo Pati Hospital. Data analysis was carried out with interactive model three steps, namely data collection, data reduction, data presentation.

Results: The results showed the clavicula examination procedure with clinical fractures in radiology installation RAA Soewondo Pati Hospital was using Antero Posterior (AP) projection.

Conclusions: The reason for using this projections is because this projections have provided diagnostic anatomy information and its enough to make a the diagnosis. But to show costae 1 and 2 and clavicle appear more clear and not superposition each other should use AP Axial projections.
\end{abstract}

Keyword : Clavicula; fracture; Antero Posterior Projections

\section{Pendahuluan}

Clavicula merupakan tulang melengkung yang membentuk bagian anterior gelang bahu. Untuk keperluan pemeriksaan, tulang ini dibagi atas batang dan dua ujung. Ujung medial disebut ekstremitas sterna dan yang bersendi dengan sternum, ujung lateral disebut ekstremitas acromial yang bersendi pada procesus acromion scapula (Syaifuddin, 2010), adapun fungsi clavicula yaitu sebagai titik tumpu untuk gerakan lengan. (Long, Rollins and Smith, 2016).

Melihat dari segi fungsi, clavicula juga memiliki beberapa kelainan diantaranya fraktur dan dislokasi (Lampignano and Kendrick, 2018). Namun yang sering terjadi ialah fraktur, fraktur merupakan gangguan dari kontinuitas yang normal dari suatu tulang. Jika terjadi fraktur, maka jaringan lunak di sekitarnya juga sering kali terganggu (Black and Hawks, 2014). Menurut Black dan Hawks (2014) Fraktur dapat diklasifikasikan menjadi fraktur tertutup dan fraktur terbuka, fraktur tertutup memiliki kulit yang masih utuh diatas lokasi cedera, sedangkan fraktur terbuka dicirikan oleh robeknya kulit diatas cedera tulang, kerusakan jaringan juga terdapat pada fraktur terbuka namun dibagi berdasarkan keparahannya.

Ada beberapa pemerikasaan, pada saat ini yang sering di jumpai pada pemeriksaan clavicula dengan menggunakan radiograf konvensional tentunya dengan kasus fraktur, persiapan pada pasien hanya meninggalkan benda-benda yang dapat mengganggu radiograf (Lampignano and Kendrick, 2018). Pada pemeriksaan radiografi clavicula posisi pasien dalam terlentang dengan lengan di samping, dagu terangkat, dan menatap lurus ke depan. Bahu posterior harus bersentuhan dengan IR atau meja, tanpa rotasi pada badan (Long, Rollins and Smith, 2016; Lampignano and Kendrick, 2018). Persiapan alat dan bahan IR ukuran $24 \times 30$, marker, plester dan gunting (Lampignano and Kendrick, 2018).

Pemeriksaan radiografi clavicula ada beberapa proyeksi diantaranya adalah proyeksi Antero posterior (AP), Antero Posterior (AP) Axial, Antero Posterior (AP) Axial Lordotic, Postero Anterior (PA) dan Postero Anterior (PA) Axial. Pemeriksaan AP Axial clavicula 
menggunakan penyudutan sebesar $15^{\circ}-30^{\mathrm{O}}$ ke arah cephalad, sedangkan pada proyeksi AP Axial Lordotic sudut yang digunakan sebesar $0^{\mathrm{O}}-15^{\mathrm{O}}$ ke arah cephalad. Proyeksi PA Axial juga menggunakan penyudutan sinar sebesar $0^{\mathrm{O}}-15^{\mathrm{O}}$ namun ke arah caudad. Proyeksi AP bertujuan untuk memperlihatkan seluruh clavicula, yakni mencakup keadaan acromio clavicula dan sterno claviculajoint. Proyeksi AP Axial pada pemeriksaan clavicula, bertujuan untuk menampakkan posisi clavicula terlempar dari scapula dan coste, hanya sisi ujung medial clavicula yang mengalami superposisi dengan costae pertama dan kedua (Long, Rollins and Smith, 2016; Lampignano and Kendrick, 2018). Akan tetapi, untuk pemeriksaan clavicula dengan klinis fraktur menurut Lampignano dan Kendrick (2018) dilakukan dua proyeksi yakni Proyeksi AP dan AP Axial.

Pemeriksaan radiografi clavicula dengan klinis fraktur di Instalasi Radiologi RSUD RAA Soewondo Pati menggunakan proyeksi Antero Posterior (AP) dengan arah sinar horizontal, apabila pasien kooperatif dilakukan dengan posisi pasien berdiri, namun jika pasien tidak kooperatif dilakukan dengan posisi tiduran dengan arah sinar vertical tegak lurus dan luas kolimasi yang digunakan mencakup di satu area clavicula. Hal ini berbeda menurut Lampignano dan Kendrick (2018) yang menggunakan proyeksi AP dan AP Axial untuk pemeriksaan clavicula dengan klinis fraktur.

Berdasarkan hal tersebut, penulis ingin mengkaji lebih lanjut mengenai proseudur pemeriksaan clavicula pada pasien dengan klinis fraktur di Instalasi Radiologi RSUD RAA Soewondo Pati dengan judul "Prosedur Pemeriksaan Radiografi Clavicula dengan Klinis Fraktur di Instalasi Radiologi RSUD RAA Soewondo Pati"

\section{Metode}

Penelitian ini merupakan penelitian deskriptif kualitatif dengan pendekatan studi kasus. Waktu penelitian pada bulan April - Mei 2020. Subyek penelitian dalam Karya Tulis Ilmiah ini adalah prosedur pemeriksaan radiografi clavicula dengan menggunakan naskah publikasi dan data yang diperoleh di RSUD RAA Soewondo Pati. Metode pengumpulan data dalam penyusunan karya tulis ilmiah ini meliputi observasi, dokumentasi dan studi pustaka. Intrumen penelitian yang digunakan yaitu pedoman observasi. Pengolahan dan analisis data dilakukan secara deskriptif dengan membuat narasi dan tabulasi terhadap naskah publikasi dan data yang diperoleh di RSUD RAA Soewondo Pati pada pemeriksaan radiografi clavicula dengan klinis fraktur, dan alasan dilakukan dengan proyeksi AP saja.

\section{Hasil dan Pembahasan}

\section{Hasil}

Persiapan pasien pada pemeriksaan radiografi clavicula dengan klinis fraktur di Instalasi Radiologi RSUD RAA Soewondo Pati tidak ada persiapan khusus bagi pasien. Pasien dipersiapkan dari ruangan atau IGD dengan melepas benda benda logam yang berada di area clavicula yang mampu mengganggu hasil radiograf. Radiografer menjelaskan prosedur pemeriksaan kepada pasien, dan meminta pasien tidak bergerak saat pemeriksaan. Persiapan alat dan bahan yang digunakan sebelum pemeriksaan adalah pesawat sinar - X siap pakai dengan kondisi yang baik dan terdapat bucky table di meja pameriksaan, kemudian imaging plate/kaset berukuran 24 x30 $\mathrm{cm}, \mathrm{CR}$ untuk prosecing film, printer dry pix.

Prosedur pemeriksaan radiografi clavicula dengan kasus fraktur dilakukan dengan proyeksi AP. Pada proyeksi AP mengatur posisi pasien tidur terlentang diatas brangkard pemeriksaan dengan bahu kanan diletakkan menempel kaset, posisi bahu kanan dari shoulder sampai MSP tubuh masuk pada kaset, mengatur central point pada pertengahan clavicula, dan mengatur luas kolimasi seluas kaset $24 \times 30 \mathrm{~cm}$.

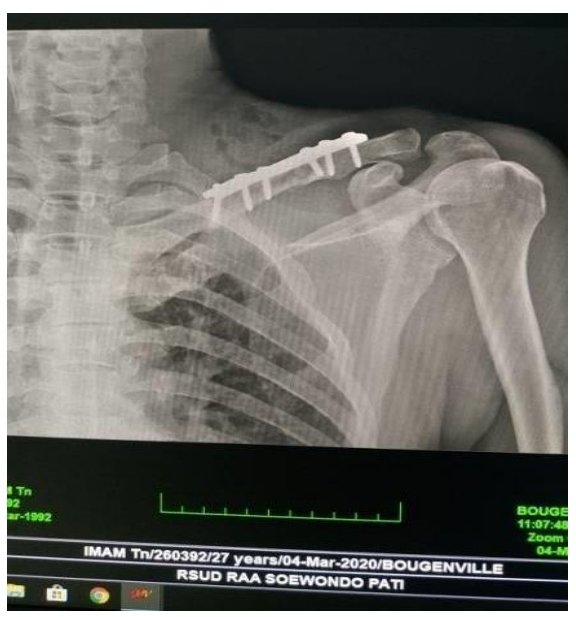

Gambar 1. Hasil radiograf pemeriksaan radiografi clavicula proyeksi AP

Berdasarkan observasi yang penulis lakukan selama di Instalasi Radiologi Rumah Sakit Umum Daerah RAA Soewondo Pati pada pemeriksaan radiografi clavicula hanya menggunakan proyeksi AP . Menggunakan proyeksi AP sesuai dengan SOP yang ada di Instalasi Radiologi Rumah Sakit Umum Daerah RAA Soewondo Pati. 


\section{Pembahasan}

1. Persiapan Pasien

Persiapan pasien pada pemeriksaan clavicula dengan klinis frakturdi Instalasi Radiologi RSUD RAA Soeowondo Pati dilakukan denganmempersiapkan dari ruangan atau IGD dengan melepas benda benda logam yang berada di objek yang akan di periksa yaitu di clavicula, hal ini sesuai dengan pernyataan yang disampaikan oleh Lampignano dan Kendrick 2018 yaitu tidak ada persiapan khusus untuk pemeriksaan radiograf clavicula.

\section{Persiapan Alat dan Bahan}

Persiapan alat pada pemeriksaan clavicula dengan klinis fraktur di Instalasi Radiologi RSUD RAA Soewondo Pati yang digunakan adalah Pesawat sinar $\mathrm{x}$, computed radiography, kaset CR ukuran $24 \times 30 \mathrm{~cm}$, hal ini sudah sesuai dengan teori yang disampaikan oleh Lampignano dan Kendrick 2018 mengenai persiapan alat dan bahan pada pemeriksaan clavicula yaitu dengan menggunakan kaset ukuran 24x30 cm serta menggunakan pesawat $\operatorname{sinar} \mathrm{x}$.

\section{Teknik Pemeriksaan Radiografi}

Teknik pemeriksaan radiografi clavicula dengan klinis fraktur clavicula dengan proyeksi AP sesuai dengan Standart Prosedur Operasional yang berlaku, namun padateori tidak relevan. Standart Prosedur Operasional (2016) yang berlaku RSUD RAA Soewondo Pati pemeriksaan clavicula menyatakan bahwa pemeriksaan radiografi clavicula dilakukan dengan proyeksi AP, sedangkan menurut teori Lampignano dan Kendrick (2018) yang menyatakan bahwa indikasi ataupun klinis fraktur clavicula sebaiknya menggunakan pemeriksaan radiografi clavicula proyeksi AP dan AP Axial namun menurut (Long, Rollins and Smith, 2016) tidak menjelaskan bahwa pada pemeriksaan radiograf clavicula dengan klinis fraktur menggunakan dua proyeksi.

Posisi pasien pada pemeriksaan radiograf clavicula dengan klinis fraktur di Instalasi Radiologi RSUD RAA Soewondo Pati, apabila pasien dalam keadaan kooperatif dilakukan dengan posisi berdiri, akan tetapi jika pasien tidak kooperatif dilakukan dengan posisi supine diatas brankard. Hal ini sesuai dengan teori Lampignano dan Kendrik (2018) yaitu pasien berdiri (erect) atau tiduran (supine) dengan punggung menempel pada meja pemeriksaan ataubucky stand.

Posisi objek pemeriksaan radiograf clavicula dengan klinis fraktur di Instalasi Radiologi RSUD
RAA Soewondo Pati yaitu dengan kedua lengan di samping tubuh pasien, kemudian mengatur kaset pada pertengahan area salah satu clavicula, hal ini sudah sesuai menurut Lampignano dan Kendrick (2018) bahwa clavicula berada pada pertengahan kaset.

Titik bidik pemeriksaan radiografi clavicula dengan klinis fraktur di Instalasi Radiologi RSUD RAA Soewondo Pati berada di pertengahan clavicula. Titik bidik yang digunakan untuk pemeriksaan clavicula sudah sesuai dengan teori Long (2016) maupun Lampignano dan Kendrick (2018) yakni titik bidik untuk pemeriksaan radiografi clavicula berada di pertengahan clavicula untuk proyeksi AP. Peneliti berpendapat bahwa titik bidik yang digunakan untuk pemeriksaan tersebut sudah baik, namun untuk melihat fraktur clavicula kurang maksimal karena pada radiograf clavicula dengan proyeksi axial tersebut tampak fraktur yang masih saling superposisi, sebaiknya ditambahkan untuk pemeriksaan radiografi clavicula dengan AP Axial.

Arah sumbu sinar pada pemeriksaan clavicula di Instalasi Radiologi RSUD RAA Soewondo Pati dengan proyeksi AP sudah sesuai teori Lampignano dan Kendrick yaitu arah sumbu sinar vertikal tegak lurus terhadap IP. Pendapat peneliti dengan menggunakan arah sumbu sinar vertikal tegak lurus dinilai kurang cukup karena radiograf kurang terfokus pada klinis dan alignment dari fraktur clavicula saling superposisi, jadi perlu proyeksi tambahan clavicula agar dapat mengetahui sejauh mana alignment dari fraktur tersebut. Sehingga pendapat peneliti, sebaiknya menggunakan pemeriksaan radiografi clavicula yang sesuai dengan teori Lampignano dan Kendrick (2018) dengan arah sinar $15^{\circ}-30^{\circ}$ kearah chepalad, yang bertujuan untuk hasil dari radiograf clavicula berada di atas scapula, medial clavicula superposisi dengan costae 1 dan 2.

Pada pemeriksaan radiograf clavicula di Instalasi Radiologi RSUD RAA Soewondo Pati menggunakan SID sebesar $100 \mathrm{~cm}$. Jarak antara fokus dan film yang digunakan pada pemeriksaan radiografi clavicula di Instalasi Radiologi RSUD RAA Soewondo Pati berbeda dengan teori Lampignano dan Kendrick (2018). Menurut Lampignano dan Kendrick (2018) SID pemeriksaan radiograf clavicula sebesar $102 \mathrm{~cm}$ sedangkan pada pemeriksaan radiografi clavicula di Instalasi Radiologi 
RSUD RAA Soewondo Pati menggunakan SIDsebesar $100 \mathrm{~cm}$. Peneliti berpendapat SID $100 \mathrm{~cm}$ pada pemeriksaan radiograf clavicula sudah mampu memberi informasi yang cukup jelas.

Proteksi radiasi di Instalasi Radiologi RSUD RAA Soewondo Pati yang diberikan kepada pasien fraktur clavicula yaitu dengan memberi luasan lapangan ekspose seluas objek yang difoto, dan memilih faktor eksposi yang tepat. Proteksi radiasi menurut teori Bontrager (2018) menyatakan memberikan gonad shield pada area yang tidak termasuk ke lapangan penyinaran, membatasi area penyinaran dengan kolimasi seoptimal mungkin, dan bekerja secara hati - hati agar tidak pengulangan foto. Peneliti berpendapat tentang penerapan proteksi radiasi yang dilakukan di RSUD RAA Soewondo Pati pada pemeriksaan ini belum sesuai dengan teori, pada pasien kali ini tidak diberikan gonad shield karena di Instalasi Radiologi RSUD RAA Soewondo Pati belum memiliki gonad shield.

\section{Alasan Menggunakan Proyeksi AP}

Prosedur pemeriksaan clavicula dengan klinis fraktur di Instalasi Radiologi RSUD RAA Soewondo Pati ini hanya dilakukan dengan menggunakan proyeksi AP. Hal ini berbeda dengan teori yang disampaikan Lampignano dan Kendrick (2018) bahwa pada pemeriksaan clavicula dengan klinis fraktur dilakukan dengan menggunakan dua proyeksi yaitu AP dan AP Axial.

Pada pemeriksaan radiograf clavicula dengan klinis fraktur di Instalasi Radiologi RSUD RAA Soewondo Pati memang dilakukan hanya proyeksi AP dikarenakan sudah sesuai Standart Prosedur Operasional Instalasi Radiologi RSUD RAA Soewondo Pati yang berlaku. Namun apabila dokter pengirim meminta permintaan untuk dilakukan AP Axial maka radiografer akan membuat permintaan foto tersebut. Dengan dilakukan hanya proyeksi AP, dokter spesialis radiologi di Instalasi Radiologi RSUD RAA Soewondo Pati sudah dapat menegakkan informasi diagnostik pada pasien tersebut.

\section{Simpulan}

1. Prosedur pemeriksaan clavicula dengan klinis fraktur di Instalasi Radiologi RSUD RAA Soewondo Pati, meliputi persiapan pasien, persiapan alat dan bahan, serta teknik pemeriksaan radiografi. Persiapan pasien pada pemeriksaan radiograf clavicula di Instalasi Radiologi RSUD RAA Soewondo Pati dengan memperhatikan posisi pasien apabila pasien kooperatif bisa berdiri maka dilakukan dengan posisi erect tapi apabila pasien dalam posisi tidak kooperatif dilakukan dengan supine menggunakan proyeksi AP. Persiapan alat dan bahan yang digunakan adalah Pesawat sinar $\mathrm{x}$, computed radiography, kaset CR ukuran 24x30, Teknik pemeriksaan radiografi clavicula dengan klinis fraktur menggunakan proyeksi AP.

2. Pemeriksaan clavicula dengan klinis fraktur di Instalasi Radiologi RSUD RAA Soewondo Pati menggunakan proyeksi AP karena proyeksi tersebut sudah memberikan informasi anatomi radiograf yang jelas dan sudah cukup untuk menegakkan diagnosa. Informasi diagnostik yang didapatkan adalah proyeksi AP sudah dapat memperlihatkan anatomi radiograf pada clavicula, sterno calviculajoin serta akromion clavicula join. Namun apabila dokter pengirim meminta untuk dilakukan pemeriksaan radiograf clavicula dengan proyeksi lain, maka radiografer akan melaksanakan sesuai permintaan.

\section{Daftar Pustaka}

Aji, Y. T. (2018) Prosedur Pemeriksaan Radiografi Clavicula Pada Kasus Fraktur Di Instalasi Radiologi RSUD K.R.M.T Wongsonegoro Semarang. Semarang: Politeknik Kesehatan Kementrian Kesehatan Semarang.

Black, J. m and Hawks, J. H. (2014) Keperawatan medika bedah: Manajemen klinis untuk hasil yang diharapkan, 3 .

J, H., S, K. and S, L. (2017) 'Clavicle Fractures: Allman and Neer Classification', Journal of Advances in Radiology and Medical Imaging, 2(1), pp. 1-11. doi: 10.15744/2456-5504.2.102. 
Lampignano, J. P. and Kendrick, L. E. (2018) 'Bontrager's Textbook of Radiographic Positioning and Related Anatomy', Elsevier.

Long, B. W., Rollins, J. H. and Smith, B. J. (2016) Merrill's Atlas Of Radiographic Positioning \& Procedures Vol. 113 edition, Journal of Lightwave Technology. doi: 10.1109/JLT.2017.2726758.

Rahmawati (2008) Pemeriksaan Clavicula Pada Kasus Fraktur di Instalasi Radiologi RSUP Dr. Sardjito Yogyakarta. Semarang: Politeknik Kesehatan Kementrian Kesehatan Semarang.

Syaifuddin (2010) Anatomi Fisiologi Kurikulum Berbasis Kompetensi untuk Keperawatan dan Kebidanan Edisi 4. Jakarta: Penerbit Buku Kedokteran EGC.

Widodo (2010) Teknik Pemeriksaan Clavicula Dengan Kasus Fraktur Pada Pasien Usia Diatas 40 Tahun di Instalasi Radiologi Rumah Sakit Panti Rahayu. Semarang: Politeknik Kesehatan Kementrian Kesehatan Semarang. 